\title{
The Museum of Gamers: Unmediated Cultural Heritage Through Gaming
}

\author{
Serdar Aydin and Marc Aurel Schnabel
}

\begin{abstract}
In the 1990s when Nicholas Negroponte published his infamous comparison between bits and atoms for Wired magazine, it was no longer strange to talk about a new concept for galleries, libraries, archives and museums (GLAMs). Pointing to a new future for libraries, Negroponte was already aware that being digital had its own reality, which was to create ambiguity in relation to the value of physicality or pure materiality, a reality that the world had been accustomed to since the Industrial Age. The Museum of Gamers, as a conceptual proposal we argue for here, sits at the convergence of these contrasting realities. On the one hand, there is a cultural artefact that has a concrete value attached to its authenticity. On the other, its digital interpretation has its own systems of values about being. And the visitor cares about a GLAM's auxiliary services as much as the objects. As information is now available everywhere, people expect a new normal from museums besides mere objects and explanatory texts next to them. As the emblematic medium of contemporary societies games offer engagement methods. Recent marketing strategies such as loyalty games and gamification prove that use of technology is moving ever closer to video games and gamedesign methods. The Museum of Gamers is a creation not only for the dissemination of cultural heritage information but also for its production through contemporary media technologies.
\end{abstract}

\footnotetext{
S. Aydin $(\bowtie) \cdot$ M.A. Schnabel

Victoria University of Wellington, Wellington, New Zealand

e-mail: Serdar.Aydin@vuw.ac.nz; MarcAurel.Schnabel@vuw.ac.nz

(C) The Author(s) 2016 


\section{Introduction}

A decade ago, William Mitchell made a reference to Louis Kahn by adapting his brick metaphor to a pixel: 'What does a pixel want to be?' (Mitchell 2005). Kahn's earlier version served to emphasise the material in architecture, whereas Mitchell stresses the 'meta-material' of digital world. This chapter looks at digital heritage and the use of contemporary media in museums. For us, whether a brick or a pixel, the aim of our thinking here is the same-it is not primarily about the technology but about people and their participatory experience.

Asymptote Architects were commissioned to design the Guggenheim Virtual Museum (GVM) in 1999. Planned to be one of the branches of the Guggenheim chain all over the world, the GVM was the first museum in cyberspace (Rashid 1999). Before the fully interactive multi-dimensional web-based environment of the GVM was launched, Alexander Galloway (author and associate professor in the Department of Media, Culture, and Communication at New York University) commented on the project in an interview-"It is exciting because 3D is a whole new realm, ready to be explored. . . If (the museum) is as good as Half Life, it will be a winner (Spingarn-Koff 2000)." Within the confines of then-current technologies, the GVM may mark the peak of the concept of the New Museology, a thought experiment on museums, which started before this millennium. However, as Galloway cynically denotes with a reference to a popular video game, new contemporary media applications likely offer more than imitating the real space of a museum in a skeuomorphic manner. In technological and economic contexts these kinds of initiatives, whether the result is a success or failure, are valuable contributions. But it would not be wrong to claim that the GVM was a model that mastered the idiosyncrasies of its physical precedents.

Moving from such a broadcast model to an internet model, the way for information to reach the receiver is multiplied. Museums have deployed the broadcasting model for many years. The inevitable change of the model forces museums to adapt. The magnitude of social media indicates heritage institutions should seek innovation. In 2012, Pennystocks designed a web page to count and display 'how quickly data is generated' through a range of social media platforms. The counter indicates that the number of uploads to Instagram exceeds 40,000 images within just a minute (Pennystocks 2014).

Digital networks create socially interactive communities online that easily create their own collections via the web. Facebook and Twitter are only two of many great examples for data aggregation all around the world. Because these networks help people tell their own stories and share contents museums may look to their participatory ways of communication to benefit from such new media technologies. However, questions of inequality and privacy also have legal and ethical implications. We can first discuss this while introducing the concept of the Museum of Gamers. 


\section{Gamers}

The Museum of Gamers is populated by gamers. But who are these gamers? The answers to this simple question may sound as inchoate as our statement is simple. Statistics may malfunction and lead us to false assumptions. Figures from the US show that the average video game player is 35 years old (ESA 2015). However, it would be biased to deduce that video games appeal particularly to young generation. The reason why game playing frequency decrease with age is dependent on a range of determinants.

Borowiecki and Prieto-Rodriguez (2014) investigates video game playing as a cultural consumption like other art activities by taking into account socioeconomic variables as well as demographic and geographic factors. They divide gamers into two groups: those who never play and those who are likely to play, adding that they are both 'heterogeneous populations'. Their results show that 'affinity with new mediums', i.e. overcoming technological barriers, is a highly significant determinant in engagement with game playing. According to experiments, gamers aged between 63 and 92 have 'higher well-being and lower depression rates' compared to peers who do not play regularly (Borowiecki and Prieto-Rodriguez 2014). In other words, video games appeal to the elderly as well as other means of cultural participation. Another grouping of gamers may be defined by gender difference, i.e. females play less than males. Apparently, the definition of gamers requires further investigation to go beyond binary conclusions while deal with the heterogeneity of gamers. But, here are gamers characterised with regards to the role they are entitled to in literature and philosophy.

Baudrillard is 'ambivalent' about gamers who, he says, express boredom from the banality of the actual world in game worlds (Coulter 2007). For him it is better to be a gamer than a jogger, who is primarily concerned about health, to engage with society in the production game. A gamer is an experimental explorer, a traveller into our future of digital realities (Baudrillard 1993). Can we generalise procedurally confined virtual spaces of game worlds as digital realities that his gamers are to explore? Baudrillard does not put it this way without a reason.

For an instant, let us ponder whether these digital realities - that we want the new museum to use so as to access an unmediated cultural heritage-can be discussed in a political manner. One of the top promoters of the Information Age, former US Vice-president Al Gore, defined a Global Information Infrastructure (GII) in a speech:

\footnotetext{
I believe that an essential prerequisite to sustainable development, for all members of the human family, is the creation of this network of networks. To accomplish this purpose, legislators, regulators, and business people must do this: build and operate a Global Information Infrastructure. This GII will circle the globe with information superhighways on which all people can travel (Mosco 2004: 39).
}

Deleuze helps us understand the nature of these superhighways with his wellknown quote: 
A control is not (no longer) a discipline. In making freeways, for example, you don't enclose people but instead multiply the means of control. I am not saying that this is the freeway's exclusive purpose, but that people can drive infinitely and 'freely' without being at all confined yet while still being perfectly controlled. This is our future. (Deleuze 1998: 18)

Thus Deleuze makes a distinction in the history of the world that was previously read as 'disciplinary societies' by Foucault. Instead, Deleuze introduces the 'societies of control' that are based on 'flexibility' which is fetishized by new mediums via all kinds of parameters and modulation tools. Today's most prevalent museum concepts emerged at the threshold of 'disciplinary societies' of postindustrial world after the 'society of sovereignty' classified within the medieval. The Brooklyn-based arts blogazine Hyperallergic makes a very good point in Twitter by asking their followers: 'Why don't more Americans go to Museums?' (Vartanian 2015). Nothing is very significant in this tweet, but the way it is carried through gives an answer. The explanation below the tweet clarifies, "in the past we may have turned to pollsters or psychics, while today we turn to Twitter to look at the hive mind and discover why..." That is the way how things work today; it is no longer a 'disciplinary society' that deploys physical means like museums for information delivery. Instead of actual documents and ink signatures there are soft-copies encrypted with codes and passwords. But what have gamers to do with this?

In Gaming: Essays on Algorithmic Culture, Galloway (2006) elaborates an intricate relationship between video games and contemporary political environments. For him video games, almost without exception, are a fetishization of "flexibility" in "informatic control" as cinema was that of the "disciplinary society" in modernity. The former privileges horizontality, wherein the latter is vertical, hiding the message in depth. However video games let the gamer "learn, internalise and become intimate with a massive, multipart algorithm." Therefore video games are an emblematic medium of the allegory that addresses directly the contemporary political expression. By "play-acting" the gamer is taught the system gradually through the gameplay. To play the game one should execute the code of the system and to win the game is to know the system. In contrast to traditional reader-text hierarchy, games reduce it on a horizontal plane, with the gamer in the act of gameplay (Galloway 2006). So far, the text may be understood as a prescription that tells museums to do games to prevent self-extinction. However play-acting easily undermines the real purpose if the key element, flexibility, is exposed to overexploitation via algorithms.

Nordin (2012a) examines the futures (plural) of the algorithmically wired world by looking at Shanghai Expo 2010. By analyzing a digital media application that visitors experience at the Siemens pavilion, she argues that there is an ambiguity between the freedom given by technology and its results that generally have contradictory impacts. The faces of visitors who enter the Siemens Pavilion are tracked and turned into avatars. Eventually, each avatar is displayed on the screen, singing a song together in the form of pre-programmed design. Every visitor has a chance to be a star only provided that she/he agrees to the condition of being an 
avatar, forfeiting identity. Nordin concludes that to build pluralistic imaginings, sustaining contestation between players within the algorithm is the solution; this is in contrast with disingenuously putting everyone into a harmonious hub defined by algorithms that eventually assimilate identities (Nordin 2012a). Her advice for contestation sounds similar to Buckminster Fuller's platonic 'World Game' where nobody is allowed to gain advantage at the expense of somebody else. But it is critical to note this difference: Nordin argues against the purely harmonious clustering of such a holistic view.

Museums can take a role in Nordin's 'futures', with a mission akin to being like a "hacker" of this system. Hackers generally do "illegal" stuff through the holes of the net. But what about a hacker being a legitimate company, asks Vincent Mosco in The Digital Sublime (2004). His exemplary case reveals a conceptual perspective in this regard. In 1999 Zero-Knowledge Systems (ZKS), based in Montreal, reacted against a code in Intel's Pentium III processor. Their website showed how to activate the embedded code which tracked user movements. Admitting the existence of the code, Intel responded with software to disguise it and even made an agreement with an anti-virus software company to turn off ZKS's "hostile code", which was virtually impossible. Mosco says that 'there is a trickster quality' in this case. In the information age, museums may have similar responsibilities to deliver 'real' information to the public. Advocated by Nordin contestation can be a key concept for such platforms.

So gamers constitute a perfect clientele profile for museums to explore gold mines hidden in information networks. Following Baudrillard's definition, the Museum of Gamers is a virtual hive that feeds and stocks our 'travellers' who allegorise Deleuze's definition of the "control societies". To allegorise means to be creative, not merely commenting or scanning through (Galloway 2006). Unmediated cultural heritage as interrogated by the RICHES Project can be then implemented. Fervent attempts to implement mere social media applications are inclined to being a part of the control society throughout its system. That would fetishize the information that is expanded by links and algorithms without fair play. In other words, as the distinction between users/creator and work/leisure is disappearing through networked relations, museums can embark on initiatives that are more ethically-engaged forms of social collectivism within digital realities.

\section{The Museum}

A very commonly-referenced diagram of the 'Reality-Virtuality (RV) Continuum' by Milgram et al. (1995) is a classification that grounds itself less on experience than on the medium (Fig. 1). As described by its authors "(it) is limited strictly to visual displays." As discussed above, the Guggenheim Virtual Museum is exemplary of this attitude by analysing a linearity between reality and virtual. The RV Continuum is ill-defined unless the reality is reduced for comparison to the same plane as the virtual. But it is possible as long as the focus is on the technological side. 


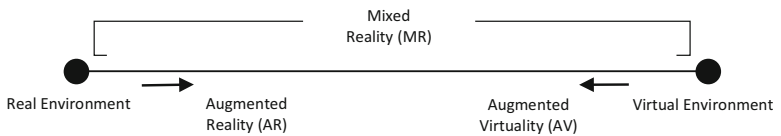

Fig. 1 Diagram of the reality-virtuality (RV) continuum (Milgram et al. 1995)

Table 1 Virtuality matrix (Richens 2014)

\begin{tabular}{l|l|l|l|l}
\hline Visitor & Site & Content & Richens' definition & Schnabel and Aydin \\
\hline Real & Real & Real & Reality & \\
\hline Real & Real & Virtual & Augmented reality & \\
\hline Real & Virtual & Real & Mixed reality & \\
\hline Real & Virtual & Virtual & N/A & Museum of gamers \\
\hline Virtual & Real & Real & Telepresence & \\
\hline Virtual & Real & Virtual & N/A & Museum of gamers \\
\hline Virtual & Virtual & Real & Virtual museum or set & \\
\hline Virtual & Virtual & Virtual & Virtual reality & \\
\hline
\end{tabular}

The diagram of the RV Continuum consists of a line between opposite ends wherein anything named as Mixed Reality (MR) if not fully real or fully virtual. MR applications include Augmented Reality (AR) and Augmented Virtuality (AV). With reference to museums, we can still refer to Richen's Virtuality Matrix for an explanation of experiences (Richens 2014). Again, this is because it is based not only on technology but in relation to visitor-site-content aspects (Table 1).

The two types of applications have not been met yet. The Museum of Gamers is located on two slots. The upper one consists of a real visitor(s), a virtual site(s) and a virtual content(s), whereas the lower one follows a virtual-real-virtual sequence. This suits Mitchell's question: "What does a pixel want?" For Murray (1998), there are three key pleasures in cyberspace: immersion, agency and transformation. Among these three, the RV Continuum and the Virtuality Matrix only touches on the first one, immersion. The fun part of cyberspace starts with the second, agency (meaningful experience) and continues with the third, transformation (fully-fledged freedom granted in digital realities). And he suggests that all of them exist in games.

The world's largest LAN (Local Area Network) party which hosted 22,180 game players was held at the DreamHack Winter 2013 in Jönköping, Sweden (GWR 2015). Calling itself "The World's Largest Digital Festival”, the event beats its own record repeatedly since its first gathering in 1994. After 20-plus years the organisation still keeps its average attendee age at 18.3 according to 2014 figures, with several hundred thousands more visitors watching online via Twitch.tv (Cordell 2014; Segal 2014). These intriguing numbers indicate that games can be more than an individual play-act, occupying online platforms, stadia and sports arenas to attract visitors at all age to socially engage with each other whether they play or not. Several similar events all over the world (e.g., Esportspool 2015) also break boundaries of time and space. 
E-sports are not fully indiscriminate though, naturally having the symptoms of games as culture (Salen and Zimmerman 2004). But the question to answer is how games create engagement, content production and interactivity in active and passive forms of experiences. Game design methods offer a wide range of techniques that are modelled in the MDA (Mechanics-Dynamics-Aesthetics) framework by Hunicke et al. (2004). Gamification that is to 'use game design elements in non-game contexts' is a controversial term in game design context (Deterding et al. 2011). We are not going to discuss this in depth. We are interested in the potential that games offer for more in-depth discoveries within and outside cyberspace. Briefly, museums can focus on the core of games instead of mere interactive screen technologies to engage people with collections. This requires a cyberperspective rather than simple virtual/real differentiations that focus on technical, or infrastructural aspects like the type of display medium even though this is easily appraised as a solution by the critics of the New Museology movement (Mancini 2008). In New York City, MoMA's collection of video games is exemplary to this kind of new curatorship that resonates with the New Aesthetic art movement that we will touch upon later (Antonelli 2012).

Going back to the "disciplinary societies" of modernity, museums served a specific audience. They formed exclusive and divisive platforms for the exposition of their collections (Ross 2004). Since the 1970s, this has changed and the idea of diverse participation at all ages has gained momentum together with movements like the New Museology (Bennett 1988). But museums are at least decades-old institutions, therefore, the New Museology had to face resistance at the beginning (Ross 2004). The profound use of internet and social media causes pressure for museum curators to seek innovative ways that meet present demands. It is no longer the collections but the services and marketing that make a difference for people. While our focus is not to show or justify apparently prevalent changes for museums, nevertheless we see a correlation between the resistance towards the New Museology and the confusion on the New Aesthetics about art mediated by computers.

The definition of unmediated cultural heritage is convergent with the New Aesthetic in which people like to tell and share their own stories through social media. James Bridle, who famed the term 'the New Aesthetic' at the SXSW interactive conference, aggregates his collection in a crudely curated way that resembles to social media's anonymousness. Bridle's collage of satellite images, pixelated screens, slit-scanned photographs and so on, is exhibited on his Tumblr (Bridle 2015a, b). While admitting that he had been collecting those items to talk about an immediate new aesthetic of the future, Bridle's blog can be seriously thought the 'museum' of what The New Aesthetics is meant to expose (Bogost 2012b). In Bridle's own words (2013):

It (the New Aesthetic) is an attempt to "write" critically about the network in the vernacular of the network itself: in a tumblr, in blog posts, in YouTube videos of lectures, tweeted reports and messages, reblogs, likes, and comments.

Bridle's introduction to the New Aesthetic quickly sparked optimistic (Borenstein 2012) as well as contrary opinions (Sterling 2012; Berry 2014). 
Sterling's response on Wired propelled much of the discussion. One of his arguments for ignoring the project as art- "machines are never our friends"- is a reflection on the scope of the New Aesthetic which is bounded to the relations between humans and computers (Sterling 2012). Borenstein then relates the New Aesthetic to a movement in philosophy called Object-Oriented-Ontology (OOO) that unprivileges the human-centric relation with other things and instead favours every possible relations between them (Bogost 2012a). Bogost (2012b) who is deeply affiliated with the OOO takes this seriously and suggests Bridle extend this relationship to a wider spectrum. Bogost's interpretation of OOO concerns the experience of objects, put with a metaphoric question:

Why stop at the unfathomability of the computer's experience when there are airports, sandstone, koalas, climate, toaster pastries, kudzu, the International 505 racing dinghy, and the Boeing 787 Dreamliner to contemplate?

As indicated in the introduction of this chapter, Mitchell had asked "what does a pixel want?" Being a video game designer, critic and researcher, Bogost makes a similarly inexplicable interrogation. In his article Bogost outlines his four suggestions for improving the New Aesthetic (Bogost 2012b):

- Look beyond humans and computers

- Take the experience of objects seriously

- Make collecting an aesthetic strategy

- Make things for understanding things, not just for human use.

Here we do not have to look into each of them specifically. These suggestions will lead us first to the New Museology movement and then to the Museum of Gamers.

The New Museology scholars offer a wide range of expectations on museums' roles, purposes, management, services, curatorship and even its relevant scholarship (McCall and Gray 2014). Among many of these, interactive multimedia technologies is one of the developments that are advocated most (Mancini 2008). This, however, does not make a shift in the relation that museums make between things presented and visitors. Objects of collections, whether interactive screen technologies or an ancient pottery, are historically mediated through such institutions. As one of Bogost's suggests, museums should look beyond humans and computers; take the experience of objects seriously; make collecting an aesthetic strategy; and make things for understanding things, not just for human use.

This may sound fictional. But "the fictional is authentic, the authentic fictional" (Ruggeri 2015). When these words were published in BBC Travel, the title of the article, "Turkey's most creative, daring idea", did not reflect the merit of The Museum of Innocence, written/built by Pamuk and Freely (2009). Rewarded as "Europe's Museum of the Year" in 2014 (EMF 2015), the museum, and/or its eponymous novel, is perhaps "the world's" most creative and daring idea.

Pamuk collected regular objects before writing his novel, The Museum of Innocence. Representing life in Istanbul, these objects are attached to a woman 
for whom the main character collects them in the novel. Being in a two-way communication, objects start to talk when the reader who is literally given a freeticket within the novel visits the actual museum that displays the objects that are collected by Pamuk for creating his masterpiece. In this sense, Pamuk takes the experience of ordinary objects seriously. Pamuk not only aggregates things but also makes an aesthetic compendium form out of them. Bogost's suggestions are in parallel with Pamuk's creative and daring idea that is also attributable to the New Museology. Introducing the items in the collection, his catalogue-brochure, The Innocence of Objects, suggests that museums should look into ephemeral details of daily life (Pamuk 2012). The Museum of Gamers is meant to address this point through games and gamers that are identified as travellers into our future in digital realities by Baudrillard (1993).

Besides services such as souvenir shops, coffee shops and restaurants, and even restrooms on which our museum preference for leisure time heavily depends, access to museums is mostly relevant with the engaging quality found in exhibitions. One example for engagement was the Demented Architecture exhibition at the City Gallery in Wellington (CGW 2015). Demented Architecture carried some of the qualities found in the New Aesthetic project.

Basically, there was a long rectangular table in the exhibition hall and white Lego pieces were left on its top to be assembled by participants. First of all, it was "collectively intelligent" inviting everybody from all age groups to join in the creation of a constantly changing, open-end art problem in the form of architectural model making. Art and architecture are more often than not relevant to high-class expertise and elitism. But Demented Architecture is comprehensible, fun and unexpected in its result, breaking the boundaries of the mythology of the architect. In a constructive manner, Demented Architecture can be seen in parallel with the New Aesthetic based on Sterling's (2012) interpretation. But what actually makes it relevant to Bridles's New Aesthetic is that it looks like an 8-bit pixelated image. The process of its transformation from one art form to another resembles to realtime aesthetics of algorithms and digital representations. These blocks create pixelated patterns which, in turn, cause problems by experiencing, in Berry's words, "digital pareidolia", that is:

"cognitive dissonance with individuals expecting (pixelated) pattern aesthetics everywhere [...] Indeed, they may seek digital or abductive explanations for certain kinds of aesthetic, visual or even non-visual which may not be digital or produced through computational means at all, a digital pareidolia." (Berry 2014)

He also identifies one more aspect of the New Aesthetics' pixelated images and blocky representations which, stemming from early 8-bit images, are "mere ornamentation in actuality... and aestheticisation of computational technology." It is therefore "firmly human mediated", although the New Aesthetic's claim is "seeing like machines' (Berry 2014). The same criticism is valid for the movement of the New Museology that focuses on mere renewal of museums' position in the society without a take-off from its nostalgia of institutional power. This discussion may lead us to a political discourse. By merely looking into social media where 
aggregation is privileged more than a compendium form (Bogost 2012a), cultural heritage will not be unmediated. The Museum of Gamers aims at creating meaningful and aesthetic construction, not just aggregation within digital realities.

\section{$4 \quad$ The Interplay}

The attempt of this chapter so far has been to extrapolate how unmediated cultural heritage through contemporary (living) media can be redeposited to museums. In the first chapter where gamers are analysed, the key reference is Nordin's conclusion on algorithmic future(s) of the world, advocating "contestation" for subjectivity specifically in interactive technologies (Nordin 2012a). Consequently, museums are appointed to a "trickster" role to occupy a vectoral space between two forces, "subjectivity" (social responsibility) and objectivity (institutional background). The Museum chapter interrogated further digital realities to show a correlation between the New Museology and the New Aesthetic. Respectively, "inclusiveness" and "indiscriminateness" from the two are discussed on the basis of Object-Oriented Ontology (Bogost 2012b).

Play is the touchstone of everything else being discussed here. Play is what gamers are addicted to. Play may refer to a do-it-yourself (DIY) manner, to decentralised and collaborative activism in its romanticism within social context, or to simply animals play-biting each other. The architectures of such romanticism matters most (Wark 2015). SimCityTM has been a historic game that is most articulated with the god-like role of architects whose sense of aesthetics are relied upon to create 'beautiful' environments for others. The game mechanics of SimCity displays a lo-res representation of supposedly real data. The play does not privilege other objects within the game, articulating a special mission to the gamer. SimCity exemplifies Nordin's criticism of contemporary digital media use. As a commercial tool, it works extremely well. For museums the architectures of play should be able to permit high-definition realities of low-class/ordinary objects. Then the behaviours, barriers, environment and the motivation of gamers together with other objects start to be of use. This is most relevant to the transformative power of play. Salen and Zimmerman (2004) explain transformative play:

(It) is a special case of play that occurs when the free movement of play alters the more rigid structure in which it takes shape. The play doesn't just occupy and oppose the interstices of the system, but actually transforms the space as a whole [...] bouncing a ball against a wall is at odds with more utilitarian uses of the architecture. At the same time, the action conforms to certain rules afforded by the formal structure of the building, leading to a particular type of architecture.

Transformative play unneccesarily requires the creative and destructive nature of people who are represented as non-players in SimCity. The game is set up as if the player, having the role of the mayor, is the god. Binarised data then is useful but the play is not transformative in the sense that it does not permit playing the game from a non-player's point of view. 
Following his keynote address at the transmediale 2015, McKenzie Wark, who writes about media theory, critical theory and new media, discusses SimCity and similar role-play games with the audience members (Catlow 2015). One of them likens it to "madness" by referring to an allegedly Einsteinien quote of 'insanity' which is "doing the same thing over and over again and expecting different results." An interesting question asked of him is "what kind of play do we need to avoid this madness?" Wark does not give a concrete reply. But he explains that "most data does not collect itself, there is human-agency involved [...] is unconscious." The moderator of the discussion, Ruth Catlow, insistingly goes over the point by asking "is it just hard to [do] that with algorithms 'replicating' artificial intelligence and artificial human feeling?" Wark's conclusion is that "it is kinda useful to think of yourself not as the playable character but as the non-player character. Most games have other humans at the background, or other figures, that are governed by the algorithm. It is like you play the game from its point of view other than from the point of view you are given" while pointing to a target that is "repurpos(ing) the game to achieve that goal because we are all non-player characters in a game that no one is controlling." Then Catlow recalls a sample: Julian Oliver's 2nd Person Shooter (2ndPS) game where the player sees through the eyes of the shooter while running away from it (Oliver 2005).

So following transformation, agency comes in relation to the experience of the player in a game. And instead of a Hegelian first-person experience, Wark's conclusion is liminal to an object-oriented operation which is distinctive to a protagonist/antagonist dogmatism. Julian Oliver's 2ndPS is a good example for critiquing this point. He explains:

"In this take on the 2nd Person Perspective, you control yourself through the eyes of the bot, but you do not control the bot; your eyes have effectively been switched. Naturally this makes action difficult when you aren't within the bot's field of view. So, both you and the bot (or other player) will need to work together, to combat each other" (Douglass 2007).

Games build experiences for players (Salen and Zimmerman 2004). In a chapter titled as "Games as the Play of Experience" in Rules of Play, Salen and Zimmerman (2004) characterise play this way:

This is play: the experience of rules set in motion. Players experience this system: as blinking pixels on a screen, as sharp electronic sounds from a speaker, as sweaty fingers on a trackball and button, as lighting-fast strategic planning. Play culminates in a whirl of perceptions and emotions, thoughts and reflexes, inside the mind and through the body of the player.

Sutton-Smith (1986) frames game experience with a model of five elements; visual scanning, auditory discriminations, motor responses, concentration and perceptual patterns of learning. Within digital realities, Oliver deploys the transformative power of play by dislocating vision on agency, which in turn immerses the player in a radical type of experience. So sensorial acts, physical reactions and cognitive mechanisms involved in games offer an aesthetic aggregation technique for the Museum of Gamers to focus on in more detail. 
To this point we have touched upon the three key pleasures of cyberspace (immersion, agency and transformation) which are all found in games (Richens and Nitsche 2005). Play is an ambiguous term by nature which is widely discussed as such in academia and literature (Sutton-Smith 1986). The scope of this work does not allow further discussion here. But now, a brief introduction to a museum of gamers will be given, which attempts to bring these aspects of digital realities together with a design-research project.

\section{A 'Museum of Gamers': Augmenting Kashgar}

"Games are serious, more serious than life"-J. Baudrillard in Seduction (1979)

Augmenting Kashgar is a design research project in the field of digital heritage, which ties together architecture, history, and game design (Aydin and Schnabel 2015). Facilitating the revitalization of Kashgar's architecture, digital platforms are being designed and developed to enable the public to actively participate in the creation, interpretation and sharing of cultural heritage information. Having started in Hong Kong in 2014, Augmenting Kashgar is planned to be a digitally- oriented museum developed at DARA (Digital Architecture Research Alliance), bringing together researchers from China, Hong Kong, Canada and New Zealand.

Kashgar is the westernmost city of China, described as "the heart of one of the most lovely and bountiful oases in all Central Asia (Starr 2013: 307)." The historical urban fabric in Kashgar is "the best-preserved example of a traditional Islamic city to be found anywhere in Central Asia (Michell et al. 2008: 79)." However, Kashgar's enduring architectural heritage is threatened by unbridled pressure from fast urban development (Florenzano et al. 2010; Aydin and Schnabel 2014). Within an organic urban fabric, Kashgar preserves a unique architectural style and outdoor life through its narrow alleyways (Fig. 2).

This old city is a product of interwoven arrangements, where strong social relationships are fundamental to its agglomeration. Pyramidised through mud-brick houses, the outdoor space in Old-Town Kashgar resembles Cedric Price's 'Fun Palace' designed for social interaction (Mathews 2006). Mechanic qualities of the Fun Palace appear in a vernacular format in Kashgar. Tangible and intangible heritage complement each other in its multifunctionality. We call it play culture in which gossiping neighbours, children playing football, and even cats play-biting each other are involved as the elements, or objects, of the game. To interpret this complexity is to allegorise the political situation. This is not meant to be hard-core and one-sided ideological politics, but refers to the system that we are all in as parts of the 'control society' as elaborated earlier. Therefore, the project automatically obtains the quality of a museum in discourse as well as in outcome.

At this point, it is useful to track back and refer to Nordin's examination on "narratives at Expo 2010 Shanghai China as an instance of the local constitution of" the world's future (Nordin 2012a, b; Schnabel and Aydin 2015). Her departure point is the Chinese concept of tianxia (all-under-heaven) which refers to a 


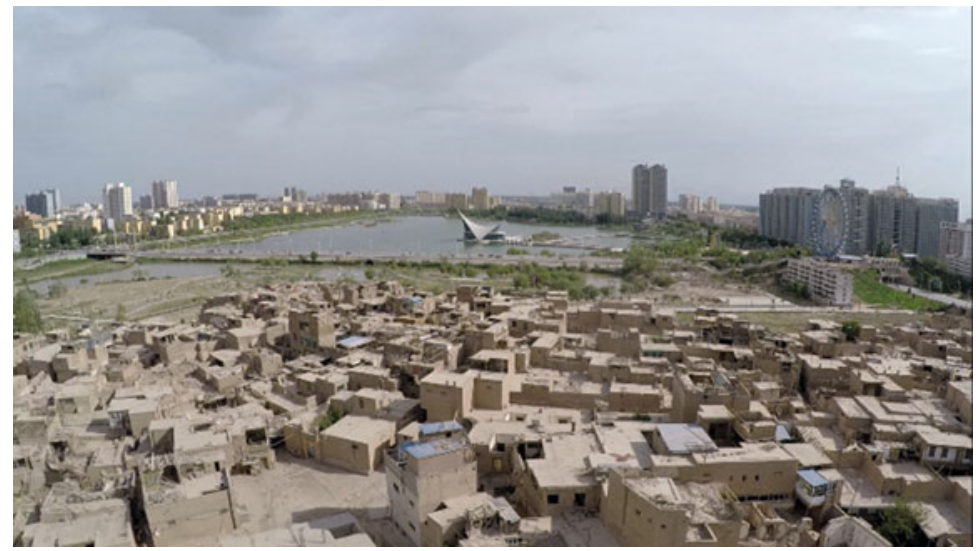

Fig. 2 Kashgar's old and new architectural exposition (Photo by S Aydin)

harmonious future. She elaborates her view via the SIEMENS pavilion that interests us most within this article. She writes:

Entering Siemens's harmonious and commercialized rendition of tianxia, we are photographed. As in a miracle of scientific development our faces appear on a film screen at the exit, manipulated to sing together in harmony with the Expo theme tune [...] We are allowed into the spotlight on the condition that we become avatars that sing simultaneously in one voice to the Chinese melody.

This accords with Deleuze's interpretation for the "societies of control". Her conclusion is that

The Expo worldview portrays itself as 'from the world', yet insists on the singular China's Future as the (Harmonious) World's Future. On this view, there is only one Future, and it does not welcome contestation [...] We can refuse scripting our songs in the pre-programmed manner suggested by pre-dominant imaginings at the Expo. It can indeed be possible to step up to the challenge of coeval multiplicities that time and space should present us with [...] Building such pluralistic imaginings of China in the world remains a task for future research.

The Augmenting Kashgar Project sits at the heart of the task that Nordin suggests for future research. To make an analogy, there are two players in this game: a top-down decision mechanism that seeks a "harmonious" future, and an ethnic minority that tries to endure its value within the circumstances of a contestation-zero atmosphere. Therefore the aim of this project is to provide this game platform without any interfering political dead-lock. Nevertheless, its message transcends the level of allegory to a creative recreation of heritage within digital realities. An unmediated form for the dissemination of Kashgar's cultural heritage information is to be designed through gaming which is to be a realm for contestation with an expectation for futures instead of The Future.

The project looks into borderlines between self-other, topophilia-topophobia and units-whole. The first is to argue about the identity, the second about the place and 
the third being the time perception. These three aspects converge with the structure of previous chapters, namely gamers, the museum and the interplay. Gamers represent agency as an identity. Separating focalisation from agency is a game design problem to address. Via alienating disassociation from agency, the game manifests itself by not privileging a single type of experience. The museum as an immersive place is created with relationship between possible game worlds. And the transformative power of contestation brings a meaningful interplay between rigid structures of real conditions and possible digital emancipations.

\section{Conclusion}

The Museum of Gamers frames a theoretical discourse on the place of living media in which games are the most dynamic. Derived from Negroponte's comparison between bits and atoms, it is emphasised that contemporary media is promising. This chapter argues that it is more than a technological change which is to burden museums into bigger responsibilities. Nevertheless the changes are seen and proven as opportunities throughout the text. The analogy of Mitchell's empathy with pixels emphasises how one of the greatest names of modern architecture, Louis Kahn, communicated poetically with a building material, namely brick. There may not be much difference between the subject-matter of architecture and that of digital realities. But our focus includes Object-Oriented-Ontology by connecting the New Museology and the New Aesthetic movements. To some extent the chapter describes the interplay where three key pleasures of cyberspace are completed by showing how they are brought together. In the last part a design-research project, Augmenting Kashgar, is briefly introduced where the core component of this project is to enable interaction with the objects in question, which are the narrow alleys of Kashgar. Interpreting the diachronic details of lived lives in Kashgar via games presents a sample task for developing an unmediated cultural heritage platform where contestation brings engagement and interactivity.

Acknowledgments This research is made possible through the support of DARA (Digital Architecture Research Alliance), Strategic Research Grant at Faculty of Architecture and Design, Victoria University of Wellington, DRS (Design Research Society) and School of Architecture at The Chinese University of Hong Kong. Special thanks to Kashgar Karamat Culture Media and Xinjiang Institute of Architectural Design and Research for their help and guidance in Kashgar.

Open Access This chapter is distributed under the terms of the Creative Commons AttributionNoncommercial 2.5 License (http://creativecommons.org/licenses/by-nc/2.5/) which permits any noncommercial use, distribution, and reproduction in any medium, provided the original author(s) and source are credited.

The images or other third party material in this chapter are included in the work's Creative Commons license, unless indicated otherwise in the credit line; if such material is not included in the work's Creative Commons license and the respective action is not permitted by statutory regulation, users will need to obtain permission from the license holder to duplicate, adapt or reproduce the material. 


\section{References}

Antonelli, P. (2012). Video games: 14 in the collection, for starters. Retrieved November 20, 2015, from http://www.moma.org/explore/inside_out/2012/11/29/video-games-14-in-the-collectionfor-starters/

Aydin, S., \& Schnabel, M. A. (2014). Augmenting Kashgar. In 20th International Conference on Virtual Systems and Multimedia, VSMM 2014, Hong Kong.

Aydin, S., \& Schnabel, M. A. (2015). Fusing conflicts within digital heritage through the ambivalence of gaming: Research through design for a digital heritage project. In Y. Ikeda, C. M. Herr, D. Holzer, S. Kaijima, M. J. Kim, \& M. A. Schnabel (Eds.), 20th International Conference of the Association for Computer-Aided Architectural Design Research in Asia, CAADRIA 2015, Daegu.

Baudrillard, J. (1993). The transparency of evil: Essays on extreme phenomena. London: Verso.

Bennett, T. (1988). Museums and the people. In R. Lumley (Ed.), The museum time-machine: Putting cultures on display. London: Comedia/Methuen.

Berry, D. M. (2014). Critical theory and the digital (Critical theory and contemporary society). London: Bloomsbury.

Bogost, I. (2012a). Alien phenomenology, or, what it's like to be a thing, posthumanities. Minneapolis: University of Minnesota Press.

Bogost, I. (2012b). The new aesthetic needs to get wider. The Atlantic. Retrieved August 28, 2015, from http://www.theatlantic.com/technology/archive/2012/04/the-new-aesthetic-needs-to-getweirder/255838/

Borenstein, G. (2012). What it's like to be a 21st century thing. The Creators Project. Retrieved August 28, 2015, from http://thecreatorsproject.vice.com/blog/in-response-to-bruce-sterlingsessay-on-the-new-aesthetic\#4

Borowiecki, K. J., \& Prieto-Rodriguez, J. (2014). Video games playing: A substitute for cultural consumptions? Journal of Cultural Economics, 39(3), 239-258.

Bridle, J. (2015a). The new aesthetic and its politics. Retrieved August 28, 2015, from http:// booktwo.org/notebook/new-aesthetic-politics/

Bridle, J. (2015b). The new aesthetic 2015. Retrieved August 28, 2015, from http://new-aesthetic. tumblr.com/

Catlow, R. (2015). Capture All_Play. In transmediale 2015, Berlin. Retrieved August 28, 2015, from https://youtu.be/E76UTcwS2wk.

CGW. (2015). Demented architecture. Wellington, New Zealand: City Gallery Wellington.

Cordell, B. (2014). Inside DreamHack summer 2014: The ultimate gamer haven. Retrieved August 28, 2015, from http://www.sticktwiddlers.com/2014/07/14/inside-dreamhack-summer-2014the-ultimate-gamer-haven/

Coulter, G. (2007). Jean Baudrillard and the definitive ambivalence of gaming. Games and Culture, 2(4), 358-365. doi:10.1177/1555412007309530.

Deleuze, G. (1998). Having an idea in cinema. In E. Kafuman \& K. J. Heller (Eds.), Deleuze and Guattari: New mappings in politics, philosophy and culture. Minneapolis: University of Minnesota Press.

Deterding, S., Dixon, D., Khaled, R., \& Nacke, L. (2011). From game design elements to gamefulness: defining "gamification". In Proceedings of the 15th International Academic MindTrek Conference: Envisioning Future Media Environments. Tampere, Finland: ACM.

Douglass, J. (2007). Aesthetics and technique in interactive fiction and new media. Santa Barbara: University of California.

EMF. (2015). European museum of the year award 2014. Retrieved August 28, 2015, from http:// www.europeanmuseumforum.info/emya/emya-2014.html

ESA. (2015). Essential facts about the computer and video game industry. Retrieved August 28, 2015, from http://www.theesa.com/article/2015-essential-facts-report-finds-nearly-half-u-splays-video-games/. 
Esportspool. (2015). Events 2015. Retrieved August 28, 2015, from https://www.esportspools. com/events

Florenzano, M., Courel, M.-F., \& De Domenico, F. (2010). Digitally conserving an endangered built heritage in Kashgar, an oasis city of the Taklimakan. Paper read at 1st WATARID International Conference on Water, Ecosystems and Sustainable Development in Arid and Semi-Arid Areas, WATARID 2006, 9-15 October 2006, at Urumqi, China.

Galloway, A. R. (2006). Gaming: Essays on algorithmic culture (Electronic mediations). Minneapolis: University of Minnesota Press.

GWR. (2015). Largest LAN party 2015. Retrieved August 28, 2015, from http://www. guinnessworldrecords.com/world-records/largest-lan-party

Hunicke, R., LeBlanc, M., \& Zubek, R. (2004). MDA: A formal approach to game design and research. Proceedings of the AAAI Challenges in Game AI Workshop.

Mancini, F. (2008). Usability of virtual museums and the diffusion of cultural heritage: Reflexions on virtual and real exhibits design, for public education and entertainment. Barcelona, Spain: Universitat Oberta de Catalunya.

Mathews, S. (2006). The fun palace as virtual architecture: Cedric price and the practices of indeterminacy. Journal of Architectural Education, 59(3), 39-48. doi:10.2307/40480644.

McCall, V., \& Gray, C. (2014). Museums and the 'new museology': Theory, practice and organisational change. Museum Management and Curatorship, 29(1), 19-35.

Michell, G., Vicziany, M., Hu, T. Y., \& Gollings, J. (2008). Kashgar: Oasis city on China's old silk road. 1st Frances Lincoln ed. London: Frances Lincoln.

Milgram, P., Takemura, H., Utsumi, A., \& Kishino, F. (1995). Augmented reality: A class of displays on the reality-virtuality continuum. In Proceedings of the SPIE: Vol. 2351 (pp. 282-292).

Mitchell, W. J. (2005). Placing words: Symbols, space, and the city. Cambridge, MA: MIT Press.

Mosco, V. (2004). The digital sublime: Myth, power, and cyberspace. Cambridge, MA: MIT Press.

Murray, J. H. (1998). Hamlet on the holodeck: The future of narrative in cyberspace. Cambridge, MA: MIT Press.

Nordin, A. (2012a). Space for the future: Exhibiting China in the world at the Shanghai Expo. China Information, 26(2), 235-249. doi:10.1177/0920203x12438000.

Nordin, A. H. M. (2012b). Taking Baudrillard to the fair: Exhibiting China in the world at the Shanghai Expo. Alternatives: Global, Local, Political, 37(2), 106-120. doi:10.1177/ 0304375412444816.

Oliver, J. (2005). 2ndPS: A 2nd person shooter. Game/Play.

Pamuk, O. (2012). The innocence of objects: The museum of innocence, Istanbul. New York: Abrams.

Pamuk, O., \& Freely, M. (2009). The museum of innocence. 1st North American ed. New York: Alfred A. Knopf.

Pennystocks. (2014). The Internet in real-time. Retrieved November 23, 2014, from http:// pennystocks.la/internet-in-real-time/

Rashid, H. (1999). The museum as a digital experience. Paper read at Proceedings of the ICOMON meetings held in Madrid, Spain, 1999.

Richens, P. (2014). Keynote: Virtual reality and cultural landscapes. In N. Gu, S. Watanabe, H. Erhan, M. H. Haeusler, W. Huang, \& R. Sosa (Eds.), The 19th International Conference on Computer-Aided Architectural Design Research in Asia, Kyoto Institute of Technology.

Richens, P., \& Nitsche, M. (2005). Mindstage: Towards a functional virtual architecture. In B. Martens \& A. Brown (Eds.), Computer aided architectural design futures 2005 (pp. 331-340). Dordrecht, The Netherlands: Springer.

Ross, M. (2004). Interpreting the new museology. Museum and Society, 2(2), 84-103.

Ruggeri, A. (2015). Turkey's most creative, daring idea. $B B C$. Retrieved March 9, 2015, from http://www.bbc.com/travel/story/20150112-turkeys-most-creative-daring-idea

Salen, K., \& Zimmerman, E. (2004). Rules of play: Game design fundamentals. Cambridge, MA: MIT Press. 
Schnabel, M. A., \& Aydin, S. (2015). Amphiboly of digital heritage: Why to create authenticity through gamification. In Digital Heritage 2015, Granada, Spain.

Segal, D. (2014). Behind league of legends, e-sports's main attraction. New York Times. Retrieved August 28, 2015, from http://www.nytimes.com/2014/10/12/technology/riot-games-league-oflegends-main-attraction-esports.html?_r=1

Spingarn-Koff, J. (2000). Guggenheim going virtual. Retrieved August 28, 2015, from http:// archive.wired.com/culture/lifestyle/news/2000/06/36741

Starr, S. F. (2013). Lost enlightenment: Central Asia's golden age from the Arab conquest to Tamerlane. Princeton, NJ: Princeton University Press.

Sterling, B. (2012). An essay on the new aesthetic. Wired. Retrieved August 28, 2015, from http:// www.wired.com/2012/04/an-essay-on-the-new-aesthetic/

Sutton-Smith, B. (1986). Toys as culture. New York: Gardner Press.

Vartanian, H. (2015). Why don't more americans go to museums? Hyperallergic. Retrieved September 4, 2015, from http://hyperallergic.com/230554/why-dont-more-americans-go-tomuseums/

Wark, M. (2015). Capture All_Play. In R. Catlow (Ed.), Transmediale 2015. Berlin. 